\title{
FAKTOR - FAKTOR YANG MEMPENGARUHI KONSUMEN DALAM PEMBELIAN JERUK DI PASAR TEMBILAHAN KOTA KABUPATEN INDRAGIRI HILIR
}

\author{
Mardani \\ Program Studi Agribisnis Fakultas Pertanian UNISI \\ Email : Mardani @gmail.com
}

\begin{abstract}
ABSTRAK
Jeruk merupakan salah satu komoditas buah-buahan yang memiliki peranan signifikan baik di pasaran dalam negeri maupun luar negeri. Hal tersebut karena jeruk merupakan tanaman buah yang mudah untuk dibudidayakan baik di iklim tropis maupun subtropis. Tujuan penelitian ini adalah : (1) untuk mengetahui faktor-faktor yang mempengaruhi perilaku konsumen dalam pembelian jeruk di pasar Tembilahan Kota Kabupaten Indragiri Hilir, (2) untuk mengetahui besarnya pengaruh faktor-faktor tersebut terhadap perilaku konsumen dalam pembelian jeruk di pasar Tembilahan Kota Kabupaten Indragiri Hilir. Metode yang digunakan adalah analisis regresi linear berganda. Pengambilan sampel dilakukan dengan cara purposive sampling. Penelitian ini menghasilkan nilai $\mathrm{R}^{2}$ sebesar $81,3 \%$, variabel yang berpengaruh signifikan terhadap perilaku konsumen dalam pembelian jeruk di pasar Tembilahan Kota adalah pendapatan $(\alpha$ $=1 \%)$, jumlah tanggungan keluarga $(\alpha=10 \%)$, harga $(\alpha=5)$. Koefesien regresi masingmasing variabel adalah dengan nilai pendapatan sebesar 1.707.000.000, jumlah tanggungan keluarga sebesar 0.319 , dan harga sebesar 0.002 .
\end{abstract}

Kata Kunci : Jeruk, Perilaku Konsumen, Regresi Linear Berganda

\begin{abstract}
ABSTRACK
Oranges are one of the fruit commodities that have a significant role both in the domestic and foreign markets. This is because oranges are fruit plants that are easy to cultivate in both tropical and subtropical climates. The purpose of this study are: (1) to determine the factors that influence consumer behavior in buying oranges in the Tembilahan Kota Indragiri Hilir District market, (2) to determine the influence of these factors on consumer behavior in buying oranges in the Tembilahan City District market Indragiri Hilir. The method used is multiple linear regression analysis. Sampling was done by purposive sampling. This study produced a R2 value of $81,3 \%$, variables that significantly influence consumer behavior in purchasing oranges in the Tembilahan Kota market are income $(\alpha=1 \%)$, number of family dependents $(\alpha=10 \%)$, price $(\alpha=5)$. Regression coefficients of each variable are with an income value of $1,707,000,000$, the number of family dependents is 0.319 , and the price is 0.002 .
\end{abstract}

Keywords: Oranges, Consumer Behavior, Multiple Linear Regression 


\section{PENDAHULUAN}

Buah jeruk merupakan salah satu buah yang masuk dalam kategori cerah untuk dikembangkan. Selain itu, masyarakat luas juga telah mengenal buah jeruk karena buah jeruk mudah dijumpai dimana saja serta dapat dikonsumsi oleh berbagai kalangan masyarakat baik kalangan atas, menengah, maupun kalangan bawah. Banyaknya jenis dan varietasnya buah jeruk yang tersedia baik itu buah lokal maupun buah impor yang bisa diperoleh di pasar modern, pasar tradisional maupun toko-toko buah dan pedagang keliling membuat konsumen dapat dengan mudah menentukan buah jeruk mana yang sesuai dengan selera dan keinginannya.

Jeruk (Citrus $s p$ ) merupakan salah satu komoditas buah-buahan yang memiliki peranan signifikan baik di pasaran dalam negeri maupun luar negeri. Hal tersebut karena jeruk merupakan tanaman buah yang mudah untuk dibudidayakan baik di iklim tropis maupun subtropis.

Bebasnya perdagangan dunia saat ini, membuat buah-buahan impor dapat dengan mudah memasuki pasaran di Indonesia.Banyaknya jenis buah jeruk, baik lokal maupun impor yang beredar di pasaran membuat konsumen harus menetapkan pilihannya dalam membeli buah jeruk yang sesuai dengan seleranya.

Menurut Kotler (2005) ada dua faktor yang mempengaruhi konsumen berada dalam keadaan bermaksud ingin membeli dan keputusan membeli. Faktor pertama adalah sikap orang lain terhadap perilaku pembelian yang dilakukan, sikap positif akan mendorong seseorang untuk memutuskan membeli suatu produk dan sebaliknya sikap negatif akan mempengaruhi seseorang untuk tidak membeli produk tersebut.

Pengetahuan mengenai karakteristik dan proses keputusan pembelian konsumen terhadap buah jeruk. Perilaku konsumen adalah tindakan-tindakan yang dilakukan individu, masyarakat kelompok atau organisasi yang berhubungan dalam proses pengambilan keputusan dalam mendapatkan, menggunakan barangbrang atau jasa ekonomis yang dapat dipenaruhi lingkungan (Mangkunegara, 2002).

Perilaku dari kebanyakan konsumen biasanya membeli lebih banyak jika harga barang tersebut turun. Sebagai contoh, harga yang lebih rendah dapat mendorong konsumen yang sudah membeli barang itu untuk membeli dalam jumlah yang lebih besar lagi, dan memungkinkan pembeli lain yang sebelumnya tidak mampu membeli barang tersebut maka akan membeli juga.

Jeruk yang dijual dengan harga yang lebih mahal bila dibandingkan dengan jeruk dari luar, cenderung hanya dimanfaatkan untuk memnuhi kebutuhan terbatas, misalnya untuk konsumsi anggota rumah tangga dalam memenuhi vitamin dalam tubuh. Masyarakat yang semakin maju tingkat pengetahuannya serta semakin meningatnya pendapatan, semakin sadar akan pentingnya kebutuhan vitamin dalam kehidupan mereka.

Untuk memenuhi dan memuaskan kebutuhan dan keinginan konsumen akan permintaan komoditi yang mereka usahakan, maka masalah kegagalan pasar atau anjloknya harga dapat di minimalisasi. Oleh sebab itu penjual buahjeruk perlu mengetahui faktor-faktor yang dapat mempengaruhi keputusan konsumen untuk membeli suatu produk. 
Semakin tinggi tingkat pendidikan masyarakat semakin tinggi tingkat pendapatan, maka semakin sadar akan kebutuhan akan vitamin dlaam kehidupan mereka. Sumber vitamin salah satunya dapat diperoleh dari buah jeruk. Tujuan penelitian ini adalah Untuk mengetahui faktor-faktor yang mempengaruhi perilaku konsumen dalam pembelian Jeruk di Pasar Tembilahan Kota Kabupaten Indragiri Hilir dan Menganalisis faktor mana yang paling dominan dalam mempengaruhi perilaku konsumen dalam melakukan pembelian Jeruk di Pasar Tembilahan Kota Kabupaten Indragiri Hilir.

\section{METODOLOGI PENELITIAN}

\subsection{Tempat dan Waktu Penelitian}

Penelitian ini dilakukan di pasar Tembilahan Kota Kabupaten Indragiri Hilir selama 3 bulan yaitu mulai Mei sampai dengan bulan Juli 2017, dengan alasan karena pasar tersebut lebih banyak terdapat penjual jeruk/ sentral penjualanpenjualan jeruk.

\subsection{Metode Pengumpulan Data}

1. Observasi, yaitu melakukan
pengamatan kegiatan yang berhubungan denganperilaku konsumen yang membeli buah jeruk di pasar Tembilahan Kota Kabupaten Indragiri Hilir.

2. Wawancara, yaitu melakukan wawancara dengan pihak pemilik yang memiliki peranan utama dalam perumusan pemasaran, pembelian konsumen dan perilaku konsumen untuk mengetahui gambaran umum faktor yang mempengaruhinya.
3. Kuesioner, responden melakukan pengisian kuesioner sesuai dengan petunjuk pengisian kuesioner.

\subsection{Jenis dan Sumber Data}

1. Data Primer

Data primer yaitu sumber data yang langsung memberikan data kepada pengumpul data (Sugiyono, 2009: 137).Pengumpulan data primer dalam penelitian ini melalui data yang diperoleh secara langsung dari responden atau narasumber dengan memberikan pertanyaan-pertanyaan melalui wawancara.

2. Data sekunder

Data sekunder diperoleh dari studi literatur yang relevan dengan penelitian seperti buku, skripsi, internet.

\subsection{Metode Pengambilan Sampel}

Adapun metode yang digunakan adalah metode survey dan yang menjadi populasi adalah Konsumen yang melakukan pembelian buah jerukdari populasi yang ada di ambil sampel sebanyak 30 orang. Penentuan sampel secara accidential sampling. Accidential sampling yaitu penarikan sampel yang dilakukan berdasarkan tujuan tertentu dari peneliti.Pemilihan dilakukan dengan alasan dapat mewakili dan memiliki wewenang serta pengetahuan yang dibutuhkan untuk memenuhi kebutuhan penelitian.

\subsection{Teknik Analisa Data}

Untuk menganalisis penelitian ini, penganalisaan data tersebut akan dilakukan analisis kuantitatif atau secara statistik dan menggunakan program SPSS (Statistical Product and Service Solution) 
versi 23,0for windows yang merupakan salah satu aplikasi komputer untuk menganalisis data statistik. Analisa data tersebut diantaranya:

\subsubsection{Analisis Regresi Linier Berganda}

Metode ini digunakan untuk mengetahui ada atau tidaknya pengaruh variabel bebas terhadap variabel terikat. Model hubungan variabel akan dianalisis sesuai dengan persamaan regresi dengan model sebagai berikut:

$Y=a+b X_{1}+b X_{2}+b X_{3}+b X_{4}+b X_{5}+e$

Dimana :

Y =Keputusan Pembelian (Jlh

Pembelian dalam kg/ bln)

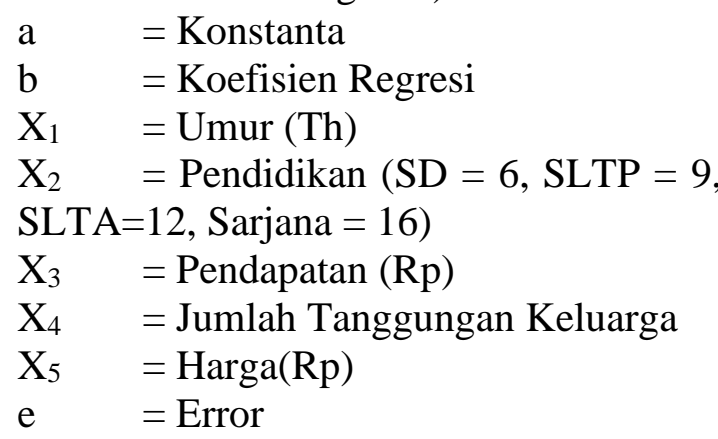

\subsubsection{Uji Hipotesis}

\section{Koefisien Determinasi $\left(\mathrm{R}^{2}\right)$}

Koefisien determinasi $\left(\mathrm{R}^{2}\right) \mathrm{di}$ gunakan untuk mengukur seberapa jauh kemampuan model dalam menerangkan variasi variabel dependen.Nilai koefisien determinasi adalah antara 0 dan 1 . Nilai $\mathrm{R}^{2}$ yang kecil bararti variabel dependen sangat terbatas (Ghozali:2005). Nilai yang mendekati 1 berarti variabel variabel independen memberikan semua informasi yang di butuhkan untuk memprediksi variasi variabel dependen.

\section{Uji Parsial (Uji t)}

Uji t-statistik di maksud untuk menguji pengaruh secara parsial antara variabel bebas terhadap variabel terikat dengan variabel lain di anggap konstan, dengan tingkat keyakinan $95 \%(\alpha=$ 0,05). Uji ini dilakukan sekaligus untuk melihat koefisien regresi secara individual varabel penelitian.

\section{Uji Simultan (uji F)}

Digunakan untuk mengetahui apakah secara simultan koefisien variabel bebas mempunyai pengaruh nyata atau tidak terhadap variabel terikat, (Sugiyono, 2009:250)

\subsubsection{Uji Asumsi Klasik}

\section{Uji Heterokedastisitas}

Uji heterokedastisitas bertujuan untuk mengetahui apakah ada model regresi ini terjadi ketidaksamaan varian dari residu satu pengamatan ke pengamatan lain. Jika varian dari residu pengamatan ke pengamatan lain berbeda berarti ada gejala heterokedastisitas dalam model regresi tersebut. Model regresi yang baik tidak terjadi adanya heteroskedastisitas. Cara yang digunakan untuk mendeteksi heteroskedastisitas adalah menggunakan scatter plot. Pada scatter plot, apabila titiknya menyebar diatas dan dibawah angka nol dan tidak membentuk pola tertentu maka model regresi bebas dari masalah heteroskedastisitas.

\section{Uji Autokorelasi}

Pengujian autokorelasi digunakan untuk mengetahui apakah terjadi korelasi antara kesalahan penganggu pada periode $\mathrm{t}$ dengan kesalahan pada periode $\mathrm{t}-1$ (sebelumnya). Model regresi yang baik adalah regresi yang bebas dari 
autokorelasi dapat dilakukan melalui pengujian terhadap nilai uji DurbinWatson (Uji DW) dengan ketentuan sebagai berikut :

\begin{tabular}{ll}
\hline Ada Autokorelasi & $0-1.224$ \\
\hline Daerah keragu-raguan & $1.224-1.553$ \\
\hline Tidak ada autokorelasi & $1.553-2.447$ \\
\hline Daerah keragu-raguan & $2.447 \quad-$ \\
& 2.776 \\
\hline Ada Autokorelasi & $2.776-4$ \\
\hline
\end{tabular}

3. Uji Multikolineritas

Uji multikolineritas bertujuan untuk menguji apakah model regresi ditemukan adanya korelasi diantara variabel independen. Jika terjadi korelasi, berarti terjadi masalah multikolinieritas. Model regresi yang baik seharusnya tidak terjadi korelasi diantara variabel independen. Untuk mendeteksi ada atau tidaknya multikolinieritas dalam model regresi dilihat dari nilai tolerance dan lawannya variance inflation factor (VIF). Kedua ukuran ini menunjukkan setiap variabel independen manakah yang dijelaskan oleh variabel independen lainnya. Tolerance mengukur variabilitas variabel independen yang terpilih dan tidak dijelaskan oleh variabel lainnya. Batasan yang umum dipakai untuk menunjukkan adanya multikolinieritas adalah nilai Tolerance $<0,10$ atau sama dengan VIF > 10 (Ghozali, 2005 ).

\section{HASIL DAN PEMBAHASAN}

\subsection{Hasil Analisis Data}

\subsubsection{Regresi Linear Berganda}

Hasil analisis penelitian ini menggunakan program SPSS 24 dengan persamaan regresi linear berganda yang dapat dilihat pada tabel 1 berikut :

Tabel 1. Koefisien Regresi Faktor-Faktor yang Mempengaruhi Pembelian Jeruk di Pasar Tembilahan Kota

\begin{tabular}{lccc}
\hline \multicolumn{1}{c}{ Variabel } & $\begin{array}{c}\text { Koefisien } \\
\text { Regresi }\end{array}$ & $\mathrm{t}-$ Hitung & Sig \\
\hline Intercept & -7.348 & -4.211 & .000 \\
Umur & .030 & 1.341 & .193 \\
Pendidikan & -.017 & -.123 & .903 \\
Pendapatan & 1.707 .000 .000 & 3.358 & $.003^{\mathrm{a}}$ \\
Jumlah Tanggungan Keluarga & .319 & 1.822 & $.081^{\mathrm{c}}$ \\
Harga & 0.002 & 2.737 & $.011^{\mathrm{b}}$ \\
\hline
\end{tabular}

Sumber : data primer diolah 2018 SPSS Versi 24
Ket a: Signifikan pada taraf $\alpha 1, \%$
b: Signifikan pada taraf $\alpha 5 \%$
$\mathrm{R}^{2}: 0,813$
c: Signifikan pada taraf $\alpha 10 \%$,
F-hitung : 20.189

Berdasarkan tabel 6 di atas, maka persamaan regresi linearnya adalah:

$Y=-7.348+0.030 X_{1}-0,017 X_{2}+1.707 E E-6 X_{3}+0,319 X_{4}+0,002 X_{5}$ 


\subsubsection{Pengujian Model}

\section{Koefisien Determinasi ( $R$ - Square/ $\mathbf{R}^{2}$ )}

Variabel pengaruh variabel bebas terhadap variabel terikat ditunjukkan oleh koefisien determinasi.Besarnya $\mathrm{R}^{2}$ (RSquare) adalah 0,813 , yang artinya 81,3 persen variasi naik turunnya pembelian Jeruk di jelaskan oleh faktor Umur, Jumlah Pendidikan dan Harga Jeruk. Sedangkan sisanya sebesar 18,7 persen dipengaruhi faktor lain yang tidak dimasukan dalam model regresi.

\section{Uji F - test}

Uji $F$ dilakukan untuk melihat pengaruh variabel independen (secara bersama-sama) terhadap variabel dependen, secara statistik. Dalam persamaan pertama dan kedua digunakan taraf keyakinan 99 persen $(\alpha=1 \%)$, maka diperoleh $F$ tabel sebesar 3.69 dari hasil regresi persamaan, diketahui bahwa nilai F-Statistic pada persamaan sebesar 20.189. Maka dengan demikian dapat disimpulkan bahwa $\mathrm{F}$ hitung $>\mathrm{F}$ tabel maka dapat diketahui bahwa umur, pendidikan, pendapatan, jumlah tanggungan keluarga dan harga jeruk berpengaruh secara simultan terhadap pembelianJeruk di kecamatan Tembilahan Kabupaten Indragiri Hilir.

\section{Uji t test}

Dari tabel 1 dapat dilihat bahwa terdapat 4 variabel yang signifikan berpengaruh terhadap pembelian buah jeruk yaitu, Pendapatan $(\alpha=1 \%)$, Jumlah Tanggungan Keluarga $\left(\mathrm{X}_{4}\right)(\alpha=10 \%)$, dan variabel Harga $(\alpha=5 \%)$. Dari persamaan tersebut dapat diinterprestasikan hasil sebagai berikut: a. Pada variabel pendapatan nilai $\mathrm{t}$ hitung 3.358lebih besar dari nilai $\mathrm{t}-$ tabel 2.059, artinya variabel pendapatan signifikan pada taraf kepercayaan $99 \%(\alpha=1 \%)$

b. Pada variabel jumlah Tanggungan Keluarga nilai $\mathrm{t}$ - hitung 1.822 lebih besar dari nilai $t$-tabel 1.485, artinyaTanggungan Keluarga signifikan dengan taraf signifkan $90 \%$ $(\alpha=10 \%)$

c. Pada variabel Harga nilai $\mathrm{t}$ - hitung 2.737 lebih besar dari nilai $\mathrm{t}$-tabel 2.059 , artinya harga signifikan dengan taraf signifkan $95 \%(\alpha=5 \%)$

\subsubsection{Uji Asumsi Klasik}

\section{Uji Multikolinearitas}

Uji multikolinearitas adalah uji untuk mengetahui apakah terdapat suatu hubungan linier antara masing-masing variabel independen di dalam model regresi. Multikolinearitas ini biasanya terjadi ketika bagian sebagian besar variabel yang digunakan saling terkait satu sama lain di dalam model. Untuk mengetahui ada tidaknya mutlikolinearitas di dalam sebuah model dapat di identifikasikan nilai $\mathrm{R}$-Square signifikan, uji f signifikan, tetpai standar eror dan tingkat singknifikan masingmasing variabel rendah.Mutlikolinearitas dapat diperiksa menggunakan Variance Inflation Faktor (VIF) untuk masingmasing variabel mempunyai nilai $\mathrm{VIF}>$ 10 berarti telah terjadi mutlikolinearitas.Beberapa ahli juga berpendapat bahwa nilai toleransi kurang dari 1 atau VIF lebih besar dari 7 menunjukkan multikolinearitas signifikan.Hasil uji multikolinearitas dapat dilihat pada tabel 2 . 
Tabel 2. Uji Multikolinieritas

\begin{tabular}{lc}
\hline \multicolumn{1}{c}{ Variabel } & VIF \\
\hline Umur $\left(\mathrm{X}_{1}\right)$ & 1.148 \\
Pendidikan $\left(\mathrm{X}_{2}\right)$ & 7.350 \\
Pendapatan $\left(\mathrm{X}_{3}\right)$ & 7.539 \\
Jumlah Tanggungan Keluarga $\left(\mathrm{X}_{4}\right)$ & 1.218 \\
Harga $\left(\mathrm{X}_{5}\right)$ & 1.016 \\
\hline
\end{tabular}

Sumber :Data Primer Diolah 2018

Berdasarkan tabel 2 dapat dilihat bahwa nilai-nilai VIF variabel $\operatorname{Umur}\left(\mathrm{X}_{1}\right)$, Pendidikan $\left(\mathrm{X}_{2}\right)$, Pendapatan $\left(\mathrm{X}_{3}\right)$, Jumlah Tanggungan Keluarga $\left(\mathrm{X}_{4}\right)$ dan Harga $\left(\mathrm{X}_{5}\right)$ nilai VIF $<10$, maka tidak terjadi multikolineritas.

\section{Uji Heterokedastisitas}

Uji heterokedastisitas bertujuan untuk menguji apakah dalam model regresi terhadi ketidaksamaan variance dari residual satu pengamatan ke pengamatan yang lain. Pendetelsoam ada tidaknya heterokedastisitas bias dilakukan dengan menggunakan metode glejser test, yaitu dengan cara meregresikan nilai absolute residual terhadap variabel independen. Hasil uji heterokedastisitas dapat dilihat pada Tabel 3, yaitu :

Tabel 3.Uji Heterokedastisitas

\begin{tabular}{lc}
\hline Variabel & Signifikansi \\
\hline Umur & 0.820 \\
Pendidikan & 0.171 \\
Pendapatan & 0.156 \\
Jumlah Tanggungan Keluarga & 0.019 \\
Harga & 0.709 \\
\hline
\end{tabular}

Sumber :Data Primer Diolah 2018

Berdasarkan tabel 3 dapat dilihat bahwa analisis dari hasil perhitungan tersebut menunjukkan bahwa variabel umur, pendidikan, pendapatan, dan harga tidak ada gangguan heterokedastisitas yang terjadi dalam estimasi parameter model penduga, dimana nilai $\mathrm{t}$ hitung yang signifikan (sig) lebih dari 0,05 sedangkan variabel jumlah tanggungan keluargaterjadi heterokedastisitas.

\section{Uji Autokorelasi}

Model regresi yang baik adalah regresi yang bebas dari autokorelasi dapat dilakukan melalui pengujian terhadap

nilai uji Durbin-Watson (Uji DW) dengan ketentuan sebagai berikut :

Ada Autokorelasi $0-1.224$

Daerah keragu-raguan

Tidak ada autokorelasi

Daerah keragu-raguan

Ada Autokorelasi

Dalam penelitian dihasilkan nilai Durbin-Watson (DW) sebesar 2.159yang berada pada interval nilai 1,553-2,447 , maka itu tidak terjadi autokorelasi. 


\subsection{Faktor-faktor yang mempengaruh Pembelian Jerukdi Pasar Kelurahan Tembilahan Kota}

\subsubsection{Pendapatan}

Variabel pendapatan berpengaruh positif dan signifikan terhadap pembelian jeruk dengan taraf kepercayaan 99\% ( $\alpha$ $=1 \%$ ) dengan koefesien regresi 1.707.000.000 yang artinya setiap penambahan pendapatan $\mathrm{Rp}$ 1/bln maka pembelian buah jeruk akan semakin meningkat sebesar $\quad 1.707 .000 .000$ $\mathrm{kg} / \mathrm{bln}$.Hal ini senada dengan penelitian yang dilakukan oleh Alfauzan (2015) bahwa pendapatan berpengaruh positif dan signifikan terhadap pembelian buah jeruk.

\subsubsection{Jumlah Tanggungan Keluarga}

Variabel jumlah tanggungan keluarga berpengaruh positif dan signifikan terhadap pembelian jeruk dengan taraf kepercayaan $90 \% \quad(\alpha=$ $10 \%$ ) dengan koefesien regresi 0.319 artinya jumlah tanggungan keluarga bertambah 1 orang maka pembelian buah jeruk akan meningkat sebesar 0.319 $\mathrm{kg} / \mathrm{bln}$.Hal ini disebabkan karena apabila jumlah tanggungan keluarga bertambah maka pembelian buah jeruk akan semakin meningkat. Hasil penelitian ini senada dengan penelitian yang dilakukan oleh Mellysa (2013) yang menyatakan bahwa jumlah tanggungan keluarga berpengaruh terhadap keputusan konsumen dalam membeli buah jeruk lokal dan jeruk impor di bandar lampung.

\subsubsection{Harga}

Variabel harga berpengaruh positif dan signifikan terhadap pembelian jeruk dengan taraf kepercayaan 95\% ( $\alpha$ $=5 \%$ ) dengan koefesien regresi 0.002artinya kenaikan harga jerukmeningkat ke pembelian buah jeruk. Apabilaharga bertambah $1 \mathrm{Rp}$ maka pembeliah buah jeruk akan meningkat sebesar $0.002 \mathrm{~kg} / \mathrm{bln}$.Hal ini dikarenakan buah jeruk mengandung vitamin $\mathrm{C}$ yang bermanfaat sebagai antioksidan dalam tubuh, yang dapat mencegah kerusakan sel akibat aktivitas molekul radikal bebas.Hal ini senada dengan penelitian yang dilakukanFerry (2014), bahwa harga berpengaruh nyata terhadap keputusan pembelian buah impor di Pasar Johar Kota Semarang.

\section{KESIMPULAN DAN SARAN}

\subsection{Kesimpulan}

Dari uraian dan penjelasan yang telah dikemukakan dalam hasil penelitian ini maka dapat disimpulkan sebagai berikut :

1. Faktor-faktor yang berpengaruh nyata terhadap perilaku konsumen dalam pembelian produk Jeruk Kecamatan Tembilahan adalah pendapatan ,jumlah Tanggungan keluarga, dan harga . Sedangkan variabel yang tidak signifikan adalah variabel Pendidikan,

2. Variabel bebas yang berpengaruh terhadap keputusan pembelian jeruk adalah sebagai berikut :

a. Pada variabel pendapatan nilai $t$ hitung 3.358 lebih besar dari nilai $t$ -tabel 2.059, artinya variabel pendapatan signifikan pada taraf kepercayaan $99 \%(\alpha=1 \%)$

b. Pada variabel jumlah Tanggungan Keluarga nilai $\mathrm{t}$ - hitung 1.822 lebih besar dari nilai $\mathrm{t}$-tabel 1.485, artinyaTanggungan Keluarga signifikan dengan taraf signifkan $90 \%(\alpha=10 \%)$ 
c. Pada variabel Harga nilai $\mathrm{t}$ - hitung 2.737 lebih besar dari nilai $\mathrm{t}$-tabel 2.059, artinya harga signifikan dengan taraf signifkan $95 \%(\alpha=$ $5 \%$ )

\subsection{Saran}

1. Sebaiknya para pedagang yang menjual jeruk melihat kesempatan untuk memasarkan produk jeruk dari faktor-faktor yang mempengaruhi perilaku konsumen.

2. Kepada penjual diharapakan dapat meningkatkan kualitas dan kuantitas produk jeruk Karena kebutuhan masyarakat yang terus meningkat akan kebutuhan akan vitamin c yang banyak terkandung dalam buah jeruk.

\section{DAFTAR PUSTAKA}

Engel, Blackwell, Miniard. (2012). Perilaku Konsumen. Tangerang: Binarupa Aksara

Hajrah, Wa Ode. 2009. Mempelajari Propile Sensori Jeruk Keprok Batu55 (Citrus reticulata blanco), Keprok Blinyu (Citrus reticulata blanco), Manis Punten (Citrus sinensis osbeck) Serta Manis Valencia (Citrus sinensis osbeck) Dengan Analisis Sensori Deskriptif. Skripsi. FakultasTeknologi Pertnian IPB. Bogor.

Ghozali, Imam.2005. Aplikai Analisis Multivarite dengan SPSS. Cetakan Keempat. Badan Penerbit
Universitas Diponegoro.

Semarang.

John C. Mowen, Michael Minor. 2002, Perilaku Konsumen (Jilid 1), Edisi Kelima, Erlangga, Jakarta.hal 312

Kotler.Philip dan Kevin Lane Keller. $2009 . \quad$ Manajemen

Pemasaran.dialih bahasakan oleh Bob Sabran. Edisi Ketiga Belas. Erlangga. Jakarta.

Mowen, JC. dan M. Minor, 2002. Perilaku Konsumen. Edisi Kelima. Alih Bahasa : Lina Salim. Penerbit erlangga, Jakarta.

Poerwanto.2004. Pengembangan JerukUnggulan

Indonesia.Makalah Semiloka Nasional Pengembangan JerukUnggulan.Bogor $10-11$ 2004.

Umar, Husein. 2008. Riset Pemasaran. Jakarta: Pt. Gramedia Pustaka Utama.

Veronika. H. S. 2008. Faktor-faktor Yang Mempengaruhi Perilaku Konsumen Terhadap Permintaan Telur Ayam Kampung (Studi kasus: Kota Medan.Propinsi Sumatera Utara).Skripsi. Universitas Sumatera Utara. Medan.

Yazid. 2005. Pemasaran Jasa: Konsep dan Implementasi. Edisi Kedua. Yogyakarta: Ekonisia FE UI. 